BMJ Paediatrics Open

\title{
Urinary tract infections in children: an overview of diagnosis and management
}

\author{
Jonathan Kaufman, ${ }^{\oplus 1,2,3}$ Meredith Temple-Smith, ${ }^{3}$ Lena Sanci ${ }^{3}$
}

To cite: Kaufman J, Temple-Smith M, Sanci L. Urinary tract infections in children: an overview of diagnosis and management. BMJ Paediatrics Open 2019;3:e000487. doi:10.1136/ bmjpo-2019-000487

Received 13 August 2019 Revised 10 September 2019 Accepted 12 September 2019

Check for updates

C Author(s) (or their employer(s)) 2019. Re-use permitted under CC BY-NC. No commercial re-use. See rights and permissions. Published by BMJ.

${ }^{1}$ Department of Paediatrics, Western Health, Sunshine Hospital, St Albans, Victoria, Australia

${ }^{2}$ Health Services Research Group, Murdoch Children's Research Institute, Parkville, Victoria, Australia

${ }^{3}$ Department of General Practice, Faculty of Medicine Dentistry \& Health Sciences, The University of Melbourne, Melbourne, Victoria, Australia

Correspondence to Dr Jonathan Kaufman; jkaufman@unimelb.edu.au

\section{ABSTRACT}

Urinary tract infections (UTIs) are a common and potentially serious bacterial infection of childhood. History and examination findings can be non-specific, so a urine sample is required to diagnose UTI. Sample collection in young precontinent children can be challenging. Bedside dipstick tests are useful for screening, but urine culture is required for diagnostic confirmation. Antibiotic therapy must be guided by local guidelines due to increasing antibiotic resistance. Duration of therapy and indications for imaging remain controversial topics and guidelines lack consensus. This article presents an overview of paediatric UTI diagnosis and management, with highlights of recent advances and evidence updates.

\section{BACKGROUND}

\section{Prevalence and epidemiology}

Urinary tract infection (UTI) is one of the most common bacterial infections of childhood. Among febrile infants, unwell children in general practice and older children with urinary symptoms, $6 \%-8 \%$ will have a UTI. ${ }^{12}$ Prevalence varies with age, peaking in young infants, toddlers and older adolescents. UTI is more common in female and uncircumcised male infants, ${ }^{1}$ understandable given bacterial skin flora concentration under the nappy in infancy, shorter female urethral distance and foreskin surface area in uncircumcised males. During toddler years, toilet training can lead to volitional holding and bladder stasis, promoting UTIs. ${ }^{3}$ Prevalence peaks again in adolescent females when sexual activity disrupts bacteria near the urethral orifice. ${ }^{1}$

Conditions that impair urinary flow increase susceptibility to UTI. Voiding flushes bacteria out of the urinary system. ${ }^{3}$ Impaired urine flow leads to urinary stasis, giving bacteria an increased reservoir and more time to establish infection. Causes of disordered voiding can be structural (urogenital anomalies) or functional (neurogenic bladder, constipation and behavioural withholding). Altered immune function can increase the risk of uncommon viral and fungal causes of UTI.

Over $30 \%$ of children with UTI will have recurrent UTI. ${ }^{4}$ Common risk factors for recurrence include vesicoureteric reflux
(VUR) and bladder-bowel dysfunction. ${ }^{4}$ Older non-continent children (eg, developmental delay) also have more recurrent UTIs.

Being such a common infection, UTI contributes a significant economic burden to the healthcare system. Use of evidence-based management has the potential for significant cost savings. ${ }^{5}$

\section{Aetiology}

Most paediatric UTIs are caused by Gram negative coliform bacteria arising from faecal flora colonising the perineum, which enter and ascend the urinary tract. ${ }^{3}$ Escherichia coli (E.coli) is the most common uropathogen, responsible for approximately $80 \%$ of paediatric UTIs. ${ }^{6}$ Uropathogenic E.coli strains possess specific properties, such as fimbriae to attach to the uroepithelial cell surface, to allow them to overcome host defences (figure 1). ${ }^{3}$ Other common uropathogens include Klebsiella, Proteus, Enterobacter and Enterococcus species. ${ }^{67}$

\section{Upper versus lower tract UTI}

UTI can be categorised anatomically into upper tract and lower tract infection. ${ }^{8}$ Upper tract UTI involves infection and inflammation in the kidneys (pyelonephritis) and ureters (figure 2). This typically leads to abdominal pain and loin tenderness, with systemic features such as fever, anorexia, vomiting, lethargy and malaise. Lower tract UTI involves infection within the bladder (cystitis) and urethra, with localised symptoms such as lower abdominal or suprapubic pain, dysuria, urinary frequency and urgency. Older children may present with signs and symptoms suggesting the site of infection. In younger patients, these classical signs are often absent, and differentiating between upper and lower UTI is less obvious.

\section{Morbidity}

Acute UTI encompasses the full spectrum of severity from mild dysuria in an otherwise well child to life-threatening urosepsis. While serious infections are less common, they can and do occur, particularly in neonates. ${ }^{9}$ Since 


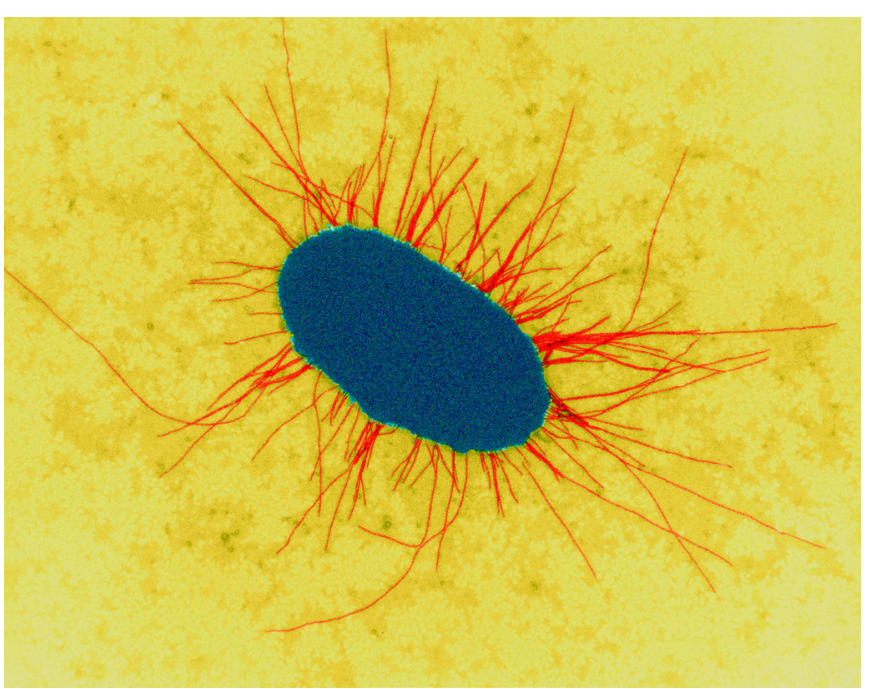

Figure 1 Escherichia coli with fimbriae. Image courtesy of Dennis Kunkel Microscopy, Science Photo Library.

routine immunisation for Haemophilus influenzae type B and Streptococcus pneumoniae, UTI has become a more common cause of occult and serious bacterial infection in infants. ${ }^{8}$

Short-term morbidity can arise from infection within the renal system. This includes systemic features including poor oral intake and dehydration, and uncommon local complications including perinephric abscess formation. Short-term morbidity also arises from haematogenous uropathogen spread. Bactaraemic UTI has been best studied in infants, as this population is most likely to have blood cultures collected during febrile illnesses. Approximately $5 \%$ of infants $<12$ months with UTI have bacteraemia identified, ${ }^{10}$ depending on study setting.

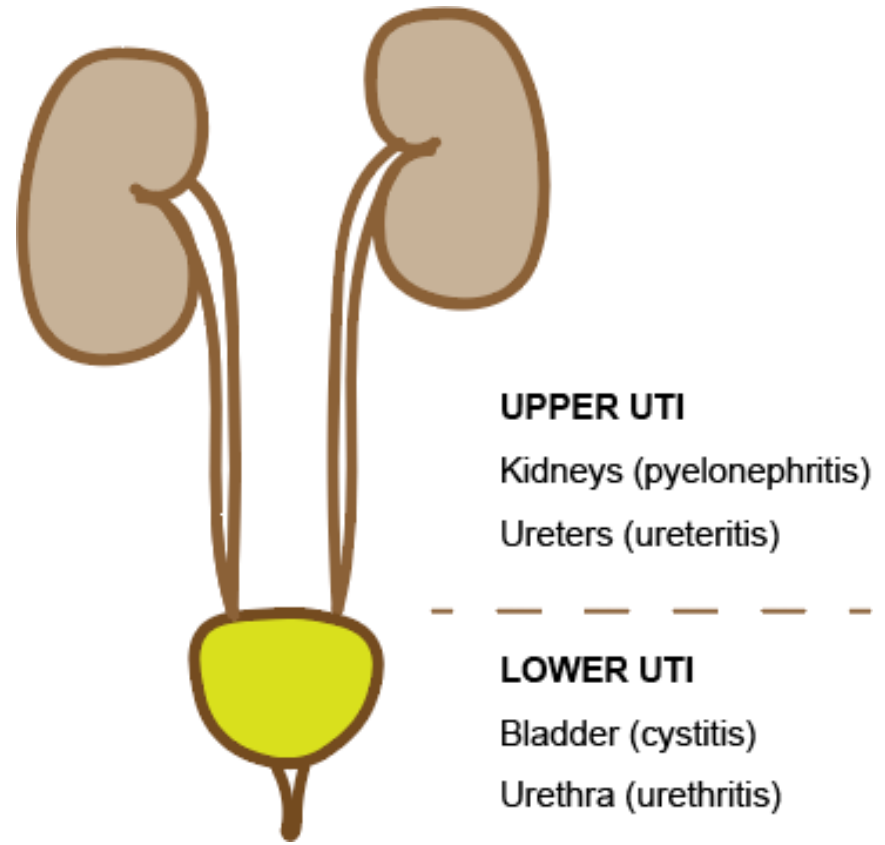

Figure 2 Urogenital system: upper versus lower tract UTI. Image courtesy of Dr Jonathan Kaufman. UTI, urinary tract infection.
Bacteraemia can then lead to urosepsis. Meningitis can also occur with haematogenous spread to the cerebrospinal fluid (CSF). The risk of coexisting meningitis and UTI is $1 \%$ in the neonatal period, ${ }^{11}$ suggesting a low threshold to perform lumbar puncture in this age group. Beyond 1 month, the risk is smaller. ${ }^{11}$ Typical empirical UTI antibiotics have poor CSF penetration and inadequate duration to treat bacterial meningitis.

Long-term morbidity follows renal injury and scarring from upper tract UTI. Around 15\% of children with first UTI who have follow-up scanning will have evidence of renal scarring. ${ }^{12}$ This scarring would be clinically important if it led to renal dysfunction, hypertension and chronic kidney disease (CKD). Historical thinking suggested these sequalae were common, leading to aggressive imaging guidelines to identify children at risk of CKD. Recent data suggest the risks are much lower. A 2011 systematic review of 1576 cases found no cases where childhood UTI was the main cause of subsequent CKD. ${ }^{13}$ Of a further 366 local CKD patients in the same study, 13 $(3 \%)$ had a history of UTI in childhood but all had renal abnormalities evident on renal ultrasound, and recurrent UTI was possibly the cause of CKD in only one case $(0.3 \%) .{ }^{13}$ Therefore, in the absence of structural renal anomalies or recurrent UTI, the risk of CKD appears minimal. Debate about the significance of post-UTI renal scarring continues.

\section{DIAGNOSIS}

Clinical features of paediatric UTI are remarkably non-specific, especially in younger children. Diagnosis can be challenging but is important to consider, especially for infants with fever without focus.

\section{History}

Younger preverbal children cannot report symptoms such as dysuria or abdominal pain. Parents often notice non-specific signs, such as lethargy, irritability, poor feeding and vomiting. These overlap with many common and benign viral infections, as well as serious bacterial infections. Fever is often present, may be the only feature present or the child may be afebrile. Malodorous or discoloured urine may be obscured in nappy-wearing children. Older children may report localising symptoms such as dysuria or flank pain.

\section{Examination}

Children with UTI may appear very well or very unwell. Fever, abdominal tenderness and dehydration may be identified. Localising signs are more likely in older children. As clinical diagnosis is unreliable, a urine sample is required for further evaluation.

\section{Urine sample collection: continent children}

Continent children can void on request to provide a midstream urine (MSU) sample into a sterile collection jar. The first voided urine flushes skin flora away from 
the urethral orifice, before sample collection from the middle of the urinary stream. Cleaning with soap and water before MSU further reduces contamination. ${ }^{14}$

\section{Urine sample collection: precontinent children}

Young children in Western society generally do not achieve urinary continence until 2-3 years old, so other collection methods are required for precontinent children. Non-invasive methods involve waiting for spontaneous urine voiding, then opportunistic collection with a nappy pad, bag, or 'clean catch' of the urine stream. These methods seem convenient and practical. However, pads and bags have high rates of contamination up to $50 \%-60 \%,{ }^{2}{ }^{15}$ understandable given their close contact with skin under the nappy area. Pad and bag samples can be useful for dipstick screening but are unreliable for culture. Cotton wool ball collection is specifically discouraged. ${ }^{16}$ Clean catch has the lowest contamination of all non-invasive methods at around $25 \%,{ }^{17}$ but attempts can be time-consuming or unsuccessful. Simple voiding stimulation methods such as the Quick-Wee technique can increase the speed and success of clean catch. ${ }^{1819}$

Invasive methods extract urine directly from the bladder by urethral catheterisation or suprapubic needle aspiration (SPA). These methods are effective but require expertise and equipment to perform and are painful and distressing for the child. Contamination from catheter and SPA is low, at $10 \%$ and $1 \%$ respectively, ${ }^{17}$ so these methods are more reliable for culture and diagnosis.
The optimal collection method remains controversial (table 1). Each method has advantages and limitations, and guidelines have different recommendations. ${ }^{20}$ In the UK, where general practitioners provide primary care, guidelines recommend clean catch or other non-invasive methods if clean catch is not possible, and catheter or SPA only if non-invasive methods are not possible or practical. ${ }^{16}$ In the USA, where paediatricians often provide primary care, guidelines recommend the opposite, that catheter or SPA is required to confirm UTI, though convenient methods such as urine bags can be used for screening. ${ }^{21}$ Most international guidelines recommend catheter or SPA as the gold standard, include clean catch as an acceptable collection method, and specifically discourage the use of bag samples for culture. ${ }^{22-24} \mathrm{~A}$ two-step process using initial bag screening and catheter confirmation of positive screens can reduce the rate of invasive procedures. ${ }^{25}$

\section{Who needs evaluation for UTI}

Clinical diagnosis of UTI is unreliable, so many children with fever or symptoms of UTI need a urine sample to exclude or make the diagnosis. Urine samples should be collected before starting antibiotics, but therapy should not be delayed in the septic child.

Children with localising signs or suspected UTI need a urine sample to confirm the diagnosis. ${ }^{16}$

Children with fever without focus, particularly neonates and infants, need a urine sample to evaluate potential

Table 1 Urine collection methods for precontinent children

\begin{tabular}{|c|c|c|c|c|c|}
\hline & \multicolumn{3}{|c|}{ Non-invasive methods } & \multicolumn{2}{|l|}{ Invasive methods } \\
\hline & Nappy pad & Urine bag & Clean catch & Catheter & SPA \\
\hline Procedure & $\begin{array}{l}\text { Pad placed inside } \\
\text { nappy. }\end{array}$ & $\begin{array}{l}\text { Bag affixed over } \\
\text { genitalia. }\end{array}$ & $\begin{array}{l}\text { Wait until child voids } \\
\text { spontaneously, } \\
\text { catch sample } \\
\text { opportunistically. }\end{array}$ & $\begin{array}{l}\text { Catheter inserted } \\
\text { into bladder via } \\
\text { urethra, removed } \\
\text { once urine sample } \\
\text { obtained. }\end{array}$ & $\begin{array}{l}\text { Needle inserted } \\
\text { into bladder } \\
\text { through skin of } \\
\text { lower abdomen } \\
\text { above pubic } \\
\text { symphisis. }\end{array}$ \\
\hline Advantages & $\begin{array}{l}\text { Convenient. } \\
\text { Useful for dipstick } \\
\text { screening. }\end{array}$ & $\begin{array}{l}\text { Convenient. } \\
\text { Useful for dipstick } \\
\text { screening. }\end{array}$ & $\begin{array}{l}\text { Least contamination } \\
\text { of non-invasive } \\
\text { methods. } \\
\text { Voiding stimulation } \\
\text { methods can } \\
\text { increase success. }\end{array}$ & $\begin{array}{l}\text { Low contamination. } \\
\text { High success rate. }\end{array}$ & $\begin{array}{l}\text { Ultra-low } \\
\text { contamination. } \\
\text { Ultrasound to } \\
\text { confirm adequate } \\
\text { bladder filling can } \\
\text { increase success. }\end{array}$ \\
\hline Limitations & $\begin{array}{l}\text { High } \\
\text { contamination. } \\
\text { Unreliable for } \\
\text { culture. }\end{array}$ & $\begin{array}{l}\text { High } \\
\text { contamination. } \\
\text { Unreliable for } \\
\text { culture. }\end{array}$ & $\begin{array}{l}\text { Moderate } \\
\text { contamination. } \\
\text { Can be time- } \\
\text { consuming. }\end{array}$ & $\begin{array}{l}\text { Invasive and } \\
\text { painful. } \\
\text { Requires } \\
\text { equipment and } \\
\text { expertise. }\end{array}$ & $\begin{array}{l}\text { Invasive and } \\
\text { painful. } \\
\text { Requires } \\
\text { equipment and } \\
\text { expertise. }\end{array}$ \\
\hline Contamination rate & $>60 \%{ }^{2}$ & $\approx 50 \%{ }^{1517}$ & $25 \%^{17}$ & $10 \%^{17}$ & $1 \%{ }^{17}$ \\
\hline $\begin{array}{l}\text { Cost per definitive } \\
\text { sample in an } \\
\text { emergency } \\
\text { department setting }\end{array}$ & - & $£ 112.28^{47}$ & $\begin{array}{l}£ 64.82 \text { standard } \\
\text { clean catch or } \\
£ 52.25 \text { with } 5 \text { min } \\
\text { voiding stimulation }{ }^{47}\end{array}$ & $£ 49.39^{47}$ & $£ 51.84^{47}$ \\
\hline
\end{tabular}

SPA, suprapubic needle aspiration. 
UTI. Outside early infancy and if the child is not unwell, it may be reasonable to wait 24 hours for collection to see if an alternative focus emerges. ${ }^{16}$

Children with an alternative focus of illness generally do not need a urine sample. ${ }^{16}$ Exceptions are septic infants, children with predisposing conditions (eg, renal anomalies), children at risk of complications (eg, single kidney) and febrile illness not following the expected clinical course.

\section{Screening - dipstick and microscopy}

Urine dipsticks are a quick, inexpensive bedside screening tool. Chemical reagent strips change colour in the presence of leucocyte esterase (an enzyme present in leucocytes) and nitrites, which may arise from UTI. ${ }^{26}$ Leucocytes generally appear in the urine in response to UTI. However, sterile pyuria can occur with other infections. Enterococcus, Klebsiella and Pseudomonas species are also less likely to produce pyuria than E.coli in children with symptomatic UTI. ${ }^{27}$ Most uropathogens convert dietary nitrates into urinary nitrites. However, not all do, including Enterococcus and Klebsiella species. ${ }^{26}$ Dipsticks are also less reliable in young infants, where frequent voiding flushes substrates out of the bladder. ${ }^{26}$

Neither leucocytes or nitrites are fully sensitive or specific for UTI, but they are a useful screening test, particularly when used in combination. If UTI is thought unlikely, dipsticks have a good negative predictive value to exclude the diagnosis. ${ }^{28}$ In the presence of suggestive symptoms and either leucocytes or nitrites, empirical antibiotics while awaiting culture is indicated. ${ }^{16}$

Urine microscopy also identifies leucocytes and bacteria, augmenting dipstick screening.

\section{Diagnosis: culture}

Laboratory culture is the gold standard for UTI diagnosis. Urine is sterile; therefore, the presence of bacteria in sufficient quantity, with concurrent evidence of active infection, suggests UTI. Urine is added to a growth medium, from which bacteria and antibiotic sensitivities are identified. Culture takes around 24 hours, then the presumptive diagnosis can be reviewed. All major UTI guidelines recommend culture is required for UTI diagnosis. ${ }^{1621}$

How many bacteria are needed to diagnose UTI in children? Thresholds vary between guidelines and collection methods. ${ }^{24}{ }^{29}$ The commonly quoted threshold of $100000 \mathrm{CFU} / \mathrm{mL}$ of a single organism is based on a seminal study in adult women by Kass ${ }^{30}$ from 1956. Does this threshold apply in children? American guidelines suggest a $50000 \mathrm{CFU} / \mathrm{mL}$ threshold with concurrent pyuria for SPA and catheter specimens. ${ }^{21}$ More recent evidence suggests an even lower $10000 \mathrm{CFU} /$ $\mathrm{mL}$ threshold would slightly increase sensitivity without reducing diagnostic specificity. ${ }^{29}$ Many guidelines suggest that any growth on SPA is abnormal, ${ }^{24}$ as SPA has negligible contamination.
Asymptomatic bacteriuria (ASB) is the presence of bacteria in the urine without active infection. ASB prevalence is estimated at $1.4 \%-1.9 \%$ in childhood. ${ }^{31} 32$ Bacterial growth without evidence of active infection (eg, pyuria) does not suggest UTI.

In reality, these diagnostic thresholds are not binary. ${ }^{16}$ Low colony counts on culture may represent early infection, contamination or ASB. Pyuria may occasionally be absent in early infection or immunocompromise. Screening and culture results must always be considered in the clinical context.

\section{Contamination}

Contamination muddies the waters when evaluating UTI. Assuming a single uropathogen causes UTI, multiple organisms suggests sample contamination. Incidental flora colonise the perigenital skin and can get flushed into the urine sample on voiding. Missed diagnosis can occur if a true uropathogen is concealed in the mix or misdiagnosis if a single contaminant dominates the culture. Contamination can be minimised by cleaning the perigenital skin before sample collection ${ }^{14}$ and avoiding touching inside the specimen jar or holding the jar against the child's skin.

\section{What is on the horizon?}

Current tests for UTI lack absolute sensitivity or specificity. Urinary biomarkers such as interleukin 6 and neutrophil gelatinase-associated lipocalin have been proposed to differentiate between active infection and ASB. Realtime PCR has been proposed to identify common uropathogens such as E.coli..$^{28}$ Further research is required to understand the clinical utility of these emerging tests.

\section{INITIAL MANAGEMENT \\ General}

Children with UTI require targeted antibiotics and supportive care. Most children with UTI can be managed at home with oral fluids and antibiotics. A small percentage will require admission for intravenous therapy, including very young and very unwell children, children with significant renal tract anomalies and children not responding to oral therapy.

\section{Antibiotic therapy}

Choice of empiric antibiotics must be guided by local guidelines, as local antimicrobial sensitivities vary significantly (table 2). The suitability of the initial agent should be reviewed once culture results are available.

Oral antibiotics are effective for the overwhelming majority of paediatric UTI. Previous Cochrane reviews suggest that short 2-4 days courses are as effective as longer 7-14 days for uncomplicated cystitis, ${ }^{33}$ while single dose therapy is less effective. ${ }^{34}$ American guidelines recommend treatment durations of 7-14 days for both cystitis and pyelonephritis, ${ }^{21}$ Canadian guidelines recommend 7-10 days, ${ }^{35}$ while National Institute for Health and 
Table 2 Recent evidence, controversies and emerging evidence

\section{RECENT EVIDENCE}

Urine bag collection

High contamination rates $\approx 50 \% .{ }^{1517}$ Least cost-effective collection method. ${ }^{47}$ Useful for dipstick screening but unreliable for culture.

Voiding stimulation methods

Improves the speed, success and cost-effectiveness of clean catch urine collection in precontinent children ${ }^{16} 18$

Antibiotic prophylaxis

Not recommended after first or second UTI in otherwise healthy children. Modest effect on recurrence, does not reduce scarring and increases antibiotic resistance. ${ }^{44-46}$

\section{CONTROVERSIES}

What colony counts on culture represent true UTI?

\section{Historical: $100000 \mathrm{CFU} / \mathrm{mL}^{30}$}

NICE: no specific recommendation. ${ }^{16}$

AAP: $50000 \mathrm{CFU} / \mathrm{mL}$ from catheter/SPA sample with pyuria. ${ }^{21}$

Proposed: $10000 \mathrm{CFU} / \mathrm{mL}$ with symptoms/pyuria. ${ }^{29}$

Duration of antibiotic therapy? courses. ${ }^{33}$

NICE: $7-10$ days for pyelonephritis and 3 days for children $>3$ months with cystitis ${ }^{16}$ AAP: 7-14 days for all UTI. ${ }^{2}$

Choice of antibiotic agent? Must be guided by local guidelines and sensitivity patterns, as susceptibility can vary significantly between regions. ${ }^{21}$

Does uncomplicated UTI Children with structurally normal kidneys appear not at significant risk of long term renal predispose to risk of chronic kidney morbidity. ${ }^{913}$

disease?

Imaging tests following UTI: who, what and when to image?
Historical: aggressive imaging to identify VUR and scarring.

NICE: age and risk based approach. ${ }^{16}$

AAP: ultrasound for all children $<2$ years old with febrile UTI, VCUG if ultrasound is abnormal. ${ }^{21}$

\section{EMERGING EVIDENCE}

Antibiotic resistance Increasing globally, highest in resource-limited settings. ${ }^{637}$ Increases healthcare costs. ${ }^{38}$

Urinary biomarkers to differentiate between UTI and asymptomatic bacteriuria

Point-of-care PCR to identify presence of uropathogens
For example, interleukin-6, neutrophil gelatinase-associated lipocalin: further research needed to establish clinical utility. ${ }^{28}$

Can identify common uropathogens but only specified targets so may miss uncommon bacterial species. Cannot differentiate between contamination, asymptomatic bacteriuria and infection. ${ }^{9}$

National Institute for Health and Care Excellence (NICE) UK Clinical Guideline 54: UTI in under 16s: diagnosis and management 2017. American Association of Paediatrics Clinical Practice Guideline: the diagnosis and management of the initial UTI in febrile infants and young children 2-24 months of age 2016.

PCR, Polymerase Chain Reaction; SPA, suprapubic needle aspiration; UTI, urinary tract infection; VCUG, Voiding Cystourethrogram; VUR, vesicoureteric reflux.

Clinical Excellence (NICE) guidelines suggests 7-10 days for pyelonephritis and a shorter 3 day course for children $>3$ months with cystitis. ${ }^{16}$ Spanish guidelines mirror NICE recommendations though single-dose therapy is recommended for children aged $>6$ years with uncomplicated cystitis. $^{36}$

Younger and sicker children may require initial intravenous therapy. Many guidelines and centres recommend admission, intravenous antibiotics and consideration of septic work-up for infants $<3$ months. ${ }^{16}$ Aim to switch to oral therapy after 48 hours if there is clinical improvement.

\section{Antibiotic resistance}

Antibiotic resistant UTI is becoming more common globally, ${ }^{637}$ increases morbidity and doubles healthcare costs. ${ }^{38}$ The usual mechanism is through acquisition of enhanced beta-lactamase enzyme properties. Some
Gram negative uropathogens can inactivate beta-lactam ring antibiotics such as penicillin and early generation cephalosporins with inherent beta-lactamase enzymes. However, some have acquired further multidrug-resistant properties through evolution of these enzymes, including the ability to hydrolyse and inactivate extended spectrum cephalosporins and carbapenem antibiotics. ${ }^{39}$ Such organisms are known as extended spectrum beta lactamase (ESBL) organisms. Prior antibiotic therapy and hospitalisation are risk factors for ESBL carriage, which then contributes to community carriage and transmission of resistance. Rates of resistant UTIs are particularly high in resource-limited settings, ${ }^{37}$ where resistance to common oral antibiotics such as ampicillin and cotrimoxazole can be as high as $97 \%-100 \% .^{40}$ 
Table 3 Summary of imaging recommendations from selected international guidelines for young children with UTI

\section{Recommended imaging test(s)}

National Institute for Health and Clinical Excellence (NICE) UK ${ }^{16}$

Age 0-6 months

Uncomplicated first UTI

Outpatient ultrasound.

Atypical UTI Inpatient ultrasound, outpatient DMSA scan and VCUG.

Recurrent UTI Inpatient ultrasound, outpatient DMSA scan and VCUG.

Age 6 months-3 years

Uncomplicated first UTI

No imaging.

Atypical UTI

Inpatient ultrasound, outpatient DMSA scan.

Recurrent UTI Outpatient ultrasound, outpatient DMSA scan.

Age $>3$ years

Uncomplicated first UTI

No imaging.

Atypical UTI Inpatient ultrasound.

Recurrent UTI Outpatient ultrasound, outpatient DMSA scan.

American Academy of Pediatrics (AAP) ${ }^{21}$

Age 0-24 months

Any febrile UTI

Ultrasound.

Complex or atypical circumstances

VCUG.

Recurrent UTI

Further evaluation.

Canadian Paediatric Society (CPS) $)^{35}$

Any febrile UTI aged $<2$ years

Ultrasound.

European Association of Urology/European Society for Paediatric Urology23

Any febrile UTI

Ultrasound.

Suspicion of VUR and/or pyelonephritis

VCUG and/or DMSA scan.

\section{Spanish Association of Paediatrics ${ }^{36}$}

\begin{tabular}{|c|c|}
\hline $\begin{array}{l}\text { UTI that requires admission, is recurrent or with } \\
\text { suspected complications }\end{array}$ & Inpatient ultrasound. \\
\hline First UTI if aged $<6$ months & Outpatient ultrasound. \\
\hline Recurrent or atypical UTI & $\begin{array}{l}\text { Outpatient ultrasound, and VCUG or contrast enhanced bladder ultrasound } \\
\text { especially if aged }<6 \text { months, and DMSA scan especially if aged }<3 \text { years. }\end{array}$ \\
\hline
\end{tabular}

Uncomplicated UTI: responds well to appropriate treatment within 48 hours.

Atypical UTI: includes very unwell/sepsis, abnormal urine flow or renal function, non-Escherichia coli uropathogen.

Recurrent UTI: $\geq 3$ episodes of cystitis or $\geq 2$ episodes of UTI including at least one episode of pyelonephritis.

Inpatient ultrasound: during acute infection.

Outpatient ultrasound: within 6 weeks.

Outpatient DMSA scan: 4-6 months following UTI to differentiate acute infection from scarring.

NICE, CPS and AAP guidelines suggest consider VCUG if abnormal ultrasound, for example, dilation suggesting severe VUR, obstruction and scarring.

DMSA, dimercaptosuccinic acid; UTI, urinary tract infection; VCUG, voiding cystourethrogram; VUR, vesicoureteric reflux.

\section{IMAGING}

Historically, guidelines recommended aggressive imaging follow-up to identify renal scarring and complications from UTI. It is now known that the most children at risk of complications have structural abnormalities identifiable on ultrasound or recurrent UTI. Therefore, many recent guidelines suggest less or no imaging after first uncomplicated UTI for older children and less aggressive imaging after recurrent UTI (table 3$){ }^{24}$

\section{Ultrasound}

Ultrasound is non-invasive, relatively inexpensive and an appropriate first-line investigation when imaging is indicated. Ultrasound can detect anatomical abnormalities and hydronephrosis or hydroureter suggesting obstruction or VUR. American and Canadian guidelines recommend ultrasound for all children aged $<2$ years with first UTI, ${ }^{21}{ }^{35}$ European Association of Urology guidelines recommend ultrasound for all children with first febrile UTI ${ }^{23}$ while NICE recommends ultrasound only for 
infants $<6$ months with first UTI unless infection is atypical or not responding to treatment. ${ }^{16}$ The NICE approach reflects the view that routine imaging after all first UTI is not cost-effective; however, imaging in younger children and other selected cases is more likely to detect findings of clinical significance. ${ }^{41}$ Ultrasound cannot exclude all cases of VUR but should detect most higher grade and clinically significant cases.

\section{Dimercaptosuccinic acid (DMSA) scan}

DMSA scan is a nuclear isotope uptake scan. Reduced uptake in the kidney can reflect either acute dysfunction (pyelonephritis) or long term damage (scarring), depending on the timing of the test. ${ }^{9}$ It is rarely required acutely but may help guide long-term management. DMSA may be indicated if UTI is atypical, recurrent or if initial ultrasound is significantly abnormal.

\section{Voiding cystourethrogram (VCUG)}

VCUG uses fluoroscopy (real-time X-ray) to identify the course of contrast inserted by bladder catheterisation. Bladder filling, emptying and ureteric reflux can be identified. While VCUG is the gold standard for identifying and quantifying VUR, the procedure has a radiation burden and is invasive.

Consensus for exactly who and how to image is lacking. Cost, invasiveness and radiation burden must be balanced against the likelihood of identifying an abnormality which may change management for the child. While most children with uncomplicated UTI outside infancy do not require any imaging, some children are at risk of longterm morbidity after UTI. Therefore, targeted imaging and surveillance strategies for children with selected indications remains appropriate.

\section{SPECIAL CASES}

Reflux: a state of flux

Historical approaches assumed VUR could lead to significant long-term renal damage, therefore should be identified early. There is now increasing awareness that much of the renal disease based on reflux is congenital, with an appreciation of mild hydronephrosis and VUR as likely normal physiological states that resolve spontaneously. ${ }^{9} 1321$ Given that lower grade reflux is unlikely to cause clinically significant scarring, and mild scarring without other risk factors is unlikely to cause long-term renal dysfunction, aggressive identification of all VUR is unwarranted. Active management strategies should still be considered for higher grade VUR (figure 3). ${ }^{12}$

\section{Anatomical abnormalities}

Anatomical abnormalities of the renal system can predispose to UTI morbidity but are now often (but not always) detected on routine antenatal ultrasound screening in developed settings. Significant abnormalities warrant appropriate follow-up.

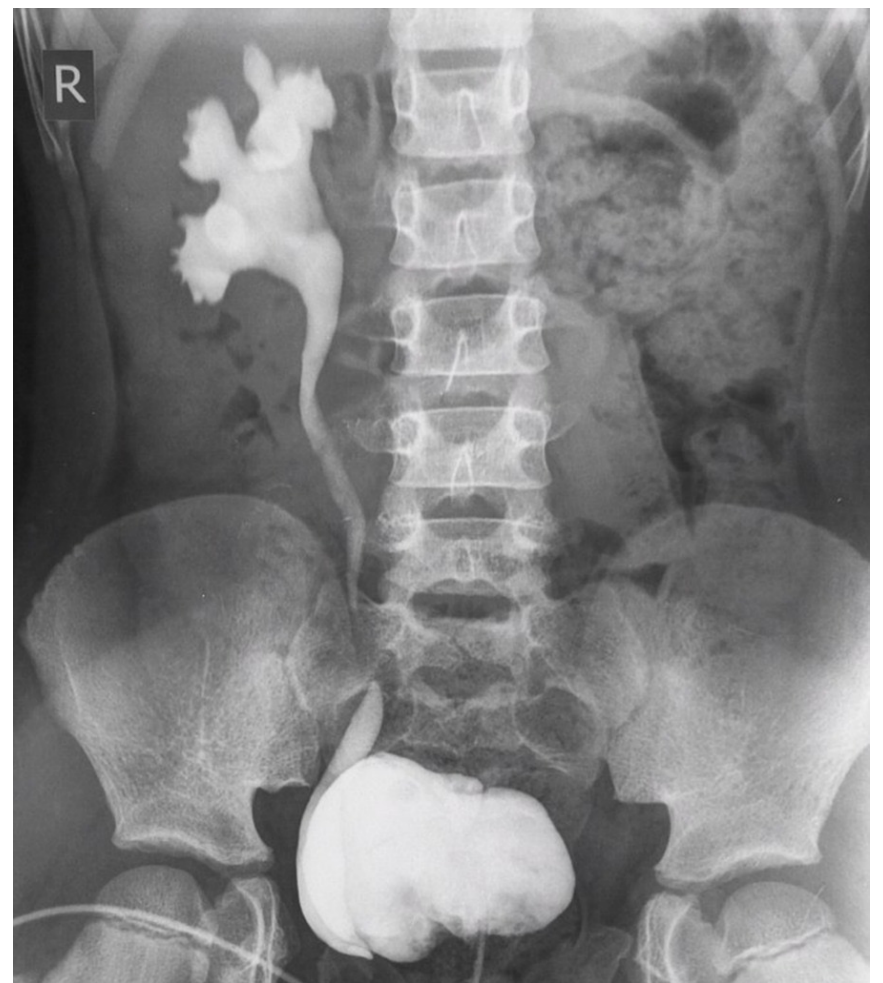

Figure 3 Five-year-old girl with unilateral grade 4 vesicouretric reflux on voiding cystourethrogram. Image courtesy of Dr Aditya Shetty, Radiopaedia.org, rID: 2722.

\section{Recurrent UTI: prophylaxis and prevention}

There are few pragmatic strategies to reduce the risk of recurrent UTI in children. Circumcision reduces the risk of UTI in males, but involves surgery, with a number needed to treat of $>100$ to prevent one UTI. ${ }^{42}$ There is insufficient evidence to support cranberry prophylaxis or probiotics. ${ }^{43}$ Antibiotic prophylaxis has modest benefits, increases antibiotic resistance ${ }^{44}$ and is not indicated after first or second UTI in otherwise healthy children. ${ }^{45}$ For children with VUR, antibiotic prophylaxis reduces UTI recurrence but does not reduce scarring. ${ }^{46}$ Simple hygiene such as wiping front to back in females can avoid introducing bacteria into the urethral orifice. Active management of toilet training and constipation is important to prevent functional bladder-bowel dysfunction. ${ }^{41}$

\section{SUMMARY}

UTI is a common bacterial infection of childhood. Clinical diagnosis is unreliable, and a urine sample is required for diagnosis, but collection is not straightforward in precontinent children. Dipstick leucocyte and nitrite screening can inform initial management while awaiting culture confirmation. Prompt management aims to prevent short-term morbidity such as urosepsis and longterm morbidity such as renal scarring. Recent evidence supports less aggressive imaging following uncomplicated UTI. Antibiotic resistance is an increasing challenge. International guidelines have conflicting recommendations regarding sample collection methods, antibiotic 
duration and imaging indications. Targeted research is required to inform knowledge gaps and inform cost-effective care for paediatric UTI.

Contributors JK drafted the manuscript, which was revised by all authors.

Funding JK is supported in part by an Australian Government Research Training Program Scholarship and Melbourne Children's Postgraduate Health Research Scholarship.

Competing interests None declared.

Patient consent for publication Not required.

Provenance and peer review Commissioned; externally peer reviewed.

Data availability statement There are no data in this work.

Open access This is an open access article distributed in accordance with the Creative Commons Attribution Non Commercial (CC BY-NC 4.0) license, which permits others to distribute, remix, adapt, build upon this work non-commercially, and license their derivative works on different terms, provided the original work is properly cited, appropriate credit is given, any changes made indicated, and the use is non-commercial. See: http://creativecommons.org/licenses/by-nc/4.0/.

\section{REFERENCES}

1. Shaikh N, Morone NE, Bost JE, et al. Prevalence of urinary tract infection in childhood: a meta-analysis. Pediatr Infect Dis $J$ 2008;27:302-8.

2. O'Brien K, Edwards A, Hood K, et al. Prevalence of urinary tract infection in acutely unwell children in general practice: a prospective study with systematic urine sampling. $\mathrm{Br} J$ Gen Pract 2013;63:e156-64.

3. Tullus K. Fifteen-minute consultation: why and how do children get urinary tract infections? Arch Dis Child Educ Pract Ed 2019. doi:10.1136/archdischild-2018-315023. [Epub ahead of print: 07 Jan 2019].

4. Keren R, Shaikh N, Pohl H, et al. Risk factors for recurrent urinary tract infection and renal scarring. Pediatrics 2015;136:e13-21.

5. NICE. Resource impact report: Urinary tract infection in under 16s: diagnosis and management (CG54): National Institute for Health and Care Excellence; 2017.

6. Edlin RS, Shapiro DJ, Hersh AL, et al. Antibiotic resistance patterns of outpatient pediatric urinary tract infections. J Urol 2013;190:222-7.

7. Zorc JJ, Kiddoo DA, Shaw KN. Diagnosis and management of pediatric urinary tract infections. Clin Microbiol Rev 2005;18:417-22.

8. Greenhow TL, Hung Y-Y, Herz AM, et al. The changing epidemiology of serious bacterial infections in young infants. Pediatr Infect Dis $J$ 2014;33:595-9.

9. Newman $\mathrm{DH}$, Shreves AE, Runde DP. Pediatric urinary tract infection: does the evidence support aggressively pursuing the diagnosis? Ann Emerg Med 2013;61:559-65.

10. Roman HK, Chang PW, Schroeder AR. Diagnosis and management of bacteremic urinary tract infection in infants. Hosp Pediatr 2015;5:1-8.

11. Tebruegge M, Pantazidou A, Clifford V, et al. The age-related risk of co-existing meningitis in children with urinary tract infection. PLoS One 2011;6:e26576.

12. Shaikh N, Craig JC, Rovers MM, et al. Identification of children and adolescents at risk for renal scarring after a first urinary tract infection: a meta-analysis with individual patient data. JAMA Pediatr 2014;168:893-900.

13. Salo J, Ikäheimo R, Tapiainen T, et al. Childhood urinary tract infections as a cause of chronic kidney disease. Pediatrics 2011;128:840-7.

14. Vaillancourt $S$, McGillivray $D$, Zhang $X$, et al. To clean or not to clean: effect on contamination rates in midstream urine collections in toilettrained children. Pediatrics 2007;119:e1288-93.

15. Ochoa Sangrador C, Pascual Terrazas A. [Systematic review of the validity of urine cultures collected by sterile perineal bags]. An Pediatr 2016;84:97-105.

16. Urinary tract infection in under $16 \mathrm{~s}$ : diagnosis and management, clinical guideline CG54. United Kingdom National Institute for Health and Care Excellence; 2017

17. Tosif S, Baker A, Oakley E, et al. Contamination rates of different urine collection methods for the diagnosis of urinary tract infections in young children: an observational cohort study. J Paediatr Child Health 2012;48:659-64.
18. Kaufman J, Fitzpatrick P, Tosif S, et al. Faster clean catch urine collection (Quick-Wee method) from infants: randomised controlled trial. BMJ 2017;357.

19. Kaufman J, Tosif S, Fitzpatrick P, et al. Quick-Wee: a novel noninvasive urine collection method. Emerg Med J 2017;34.

20. Kaufman J. How to... collect urine samples from young children. Arch Dis Child Educ Pract Ed 2019. doi:10.1136/ archdischild-2019-317237. [Epub ahead of print: 23 Aug 2019].

21. Subcommittee on Urinary Tract Infection. Reaffirmation of AAP clinical practice guideline: the diagnosis and management of the initial urinary tract infection in febrile infants and young children 2-24 months of age. Pediatrics 2016;138:e20163026.

22. Royal Children's Hospital. Statewide Victorian \& Royal Children's Hospital Clinical Practice Guideline Urinary Tract Infection, 2017. Available: https://www.rch.org.au/clinicalguide/guideline_index/ Urinary Tract Infection Guideline/\#URINARY SPECIMENS [Accessed 5 Jun 2019].

23. Stein R, Dogan HS, Hoebeke $P$, et al. Urinary tract infections in children: EAU/ESPU guidelines. Eur Urol 2015;67:546-58.

24. Okarska-Napierała M, Wasilewska A, Kuchar E. Urinary tract infection in children: Diagnosis, treatment, imaging - Comparison of current guidelines. J Pediatr Urol 2017:13:567-73.

25. Lavelle JM, Blackstone MM, Funari MK, et al. Two-Step process for ED UTI screening in febrile young children: reducing catheterization rates. Pediatrics 2016;138:e20153023.

26. Cyriac J, Holden K, Tullus K. How to use... urine dipsticks. Arch Dis Child Educ Pract Ed 2017;102:148-54.

27. Shaikh N, Shope TR, Hoberman A, et al. Association between Uropathogen and pyuria. Pediatrics 2016;138:e20160087.

28. Fritzenwanker M, Imirzalioglu C, Chakraborty T, et al. Modern diagnostic methods for urinary tract infections. Expert Rev Anti Infect Ther 2016;14:1047-63.

29. Primack W, Bukowski T, Sutherland R, et al. What urinary colony count indicates a urinary tract infection in children? J Pediatr 2017;191:259-61.

30. Kass EH. Asymptomatic infections of the urinary tract. Trans Assoc Am Physicians 1956;69:56-64.

31. Wettergren B, Jodal U. Spontaneous clearance of asymptomatic bacteriuria in infants. Acta Paediatr 1990;79:300-4.

32. Asymptomatic bacteriuria in schoolchildren in Newcastle upon Tyne. Arch Dis Child 1975;50:90-102.

33. Michael M, Hodson EM, Craig JC, et al. Short versus standard duration oral antibiotic therapy for acute urinary tract infection in children. Cochrane Database Syst Rev 2003;23.

34. Fitzgerald A, Mori R, Lakhanpaul M, et al. Antibiotics for treating lower urinary tract infection in children. Cochrane Database Syst Rev 2012;19.

35. Robinson JL, Finlay JC, Lang ME, et al. Urinary tract infections in infants and children: diagnosis and management. Paediatr Child Health 2014;19:315-9.

36. Pineiro Perez R, Cilleruelo Ortega MJ, Ares Alvarez J, et al. [Recommendations on the diagnosis and treatment of urinary tract infection]. Anales de pediatria 2019;90:400.e1-00.e9.

37. Bryce A, Hay AD, Lane IF, et al. Global prevalence of antibiotic resistance in paediatric urinary tract infections caused by Escherichia coli and association with routine use of antibiotics in primary care: systematic review and meta-analysis. $B M J$ 2016;352:1939

38. Nieminen O, Korppi M, Helminen M. Healthcare costs doubled when children had urinary tract infections caused by extendedspectrum $\beta$-lactamase-producing bacteria. Acta Paediatr 2017;106:327-33.

39. Murray TS, Peaper DR. The contribution of extended-spectrum $\beta$-lactamases to multidrug-resistant infections in children. Curr Opin Pediatr 2015;27:124-31.

40. Msaki BP, Mshana SE, Hokororo A, et al. Prevalence and predictors of urinary tract infection and severe malaria among febrile children attending Makongoro health centre in Mwanza City, north-western Tanzania. Arch Public Health 2012;70:4.

41. Urinary tract infection in children: diagnosis, treatment and longterm management London, England: National Institute for health and clinical excellence, 2007. Available: http://www.nice.org.uk/ nicemedia/live/11819/36032/36032.pdf [Accessed May 4 2012].

42. Singh-Grewal D, Macdessi J, Craig J. Circumcision for the prevention of urinary tract infection in boys: a systematic review of randomised trials and observational studies. Arch Dis Child 2005;90:853-958.

43. Schwenger EM, Tejani AM, Loewen PS, et al. Probiotics for preventing urinary tract infections in adults and children. Cochrane Database Syst Rev 2015;12. 
44. Williams G, Craig JC, Cochrane Kidney and Transplant Group. LongTerm antibiotics for preventing recurrent urinary tract infection in children. Cochrane Database Syst Rev 2011;39(Suppl 1).

45. Hewitt IK, Pennesi M, Morello W, et al. Antibiotic prophylaxis for urinary tract infection-related renal scarring: a systematic review. Pediatrics 2017;139:e20163145.
46. Hoberman A, Greenfield SP, Mattoo TK, et al. Antimicrobial prophylaxis for children with vesicoureteral reflux. N Engl J Med 2014;370:2367-76.

47. Kaufman J, Knight AJ, Bryant PA, et al. Liquid gold: the costeffectiveness of urine sample collection methods for young precontinent children. Arch Dis Child 2019. doi:10.1136/ archdischild-2019-317561. [Epub ahead of print: 23 Aug 2019]. 